\title{
FLUÊNCIA DE LEITURA: EVOLUÇÃO DO CONSTRUTO E RELAÇÕES COM A COMPREENSÃO
}

Amanda Oliveira Meggiato ${ }^{\mathrm{I}}$

Helena Vellinho Corso II

Luciana Vellinho Corso III

I Universidade Federal do Rio Grande do Sul (UFRGS), Porto Alegre (RS), Brasil; amandameggiato@gmail.com

II Universidade Federal do Rio Grande do Sul (UFRGS), Porto Alegre (RS), Brasil; hvcorso@gmail.com

III Universidade Federal do Rio Grande do Sul (UFRGS), Porto Alegre (RS), Brasil; luciana.corso@ufrgs.br

\section{Resumo}

Há diferentes definições de fluência de leitura, e, mesmo existindo consenso crescente de que envolva precisão, automaticidade e prosódia, as definições não deixam claro se a fluência contribui para a compreensão, ou se a compreensão promove fluência, ou se a relação é recíproca. Esta revisão integrativa investiga, descreve e compara tais definições, objetivando examinar como elas abordam a relação entre fluência e compreensão. Os resultados apontam que, ao incluir a prosódia na definição, fica claro que um nível de compreensão é necessário para a leitura fluente, indicando uma relação recíproca entre fluência e compreensão. As conclusões mostram a necessidade de direcionar as pesquisas para melhor refinamento e operacionalização do construto. Desdobramentos pedagógicos são sugeridos.

LEITURA • FLUÊNCIA • COMPREENSÃO DO TEXTO

\section{READING FLUENCY: HOW THE CONSTRUCT HAS DEVELOPED AND ITS RELATIONSHIP TO COMPREHENSION}

\begin{abstract}
There are different definitions of reading fluency and, even though there is a growing consensus that reading fluency involves accuracy, automaticity and prosody, the definitions make it unclear whether fluency contributes to comprehension, whether comprehension promotes fluency, or whether the relationship is reciprocal. This integrative review investigates, describes and compares such definitions, aiming to examine how they address the relationship between fluency and comprehension. The results show that when including prosody in the definition of fluency, it is clear that some level of comprehension is necessary for fluent reading, showing a reciprocal relationship between fluency and comprehension. The conclusions emphasize the importance of directing research towards a better refinement and operationalization of the construct. Pedagogical developments are suggested.
\end{abstract}




\section{FLUIDEZ LECTORA: EVOLUCIÓN DEL CONSTRUCTO Y RELACIONES CON LA COMPRENSIÓN}

\section{Resumen}

Hay diferentes definiciones de fluidez de lectura e, incluso existiendo un consenso creciente de que implica precisión, automaticidad y prosodia, las definiciones no dejan claro si la fluidez contribuye a la comprensión, o si la comprensión promueve la fluidez, o si la relación es recíproca. Esta revisión integradora investiga, describe y compara tales definiciones, con el objetivo de examinar cómo abordan la relación entre la fluidez y la comprensión. Los resultados indican, al incluir prosodia en la definición, está claro que un nivel de comprensión es necesario para una lectura fluida, lo que indica una relación recíproca entre fluidez y comprensión. Las conclusiones muestran la necesidad de dirigir la investigación para un mejor refinamiento y operacionalización del constructo. Se sugieren desdoblamientos pedagógicos.

\section{LECTURA • FLUIDEZ • COMPRENSIÓN DE TEXTO}

\section{FLUIDITÉ DE LA LECTURE : ÉVOLUTION DE LA CONCEPTION ET SES RAPPORTS AVEC LA COMPRÉHENSION}

\section{Résumé}

Plusieurs définitions de la fluidité en lecture coexistent mais, malgré un consensus croissant sur le fait que celle-ci implique la précision, l'automaticité et la prosodie, ces définitions n'indiquent pas clairement si la fluidité contribue à la compréhension, si c’est la compréhension qui favorise la fluidité ou si la relation est réciproque. Cette révision intégrative se propose d'investiguer, de décrire et de comparer ces définitions pour examiner leur façon d'aborder la relation entre fluidité et compréhension. Les résultats montrent clairement que lorsque la prosodie est prise en compte, un niveau de compréhension est nécessaire à l'acquisition d'une lecture fluide, indiquant une relation réciproque entre fluidité et compréhension. Les conclusions montrent qu'il faut orienter les recherches pour mieux raffiner et opérationnaliser cette conception. Des développements pédagogiques sont proposés à cette fin.

\section{LECTURE • FLUIDITÉ • COMPRÉHENSION DE TEXTE}


LEITURA, DE ACORDO COM A ABORDAGEM DA NEUROPSICOLOGIA COGNITIVA, caracteriza-se como um processo que se inicia pela habilidade de reconhecimento de palavras, avança com o desenvolvimento da fluência e resulta na habilidade de compreender textos (Corso et al., 2017). No entanto, as numerosas pesquisas na área têm se dedicado à investigação do reconhecimento de palavras e da compreensão apenas, sendo escassos os estudos nacionais e internacionais que abordam a fluência de leitura. Há algumas décadas, o construto tem sido considerado o resultado imediato do reconhecimento proficiente de palavras (Kuhn et al., 2010). The Literacy Dictionary define a fluência, por exemplo, como a facilidade no reconhecimento de palavras (Harris \& Hodges, 1995). Desse modo, ao longo dos anos, os esforços educacionais foram direcionados ao desenvolvimento da decodificação, enquanto a fluência foi negligenciada pelas instituições de ensino e também por pesquisadores da área (Kuhn et al., 2010).

Nos últimos anos, o entendimento sobre o que envolve a fluência leitora vem sendo ampliado. Mudança que se deve, em parte, à inclusão do construto como uma das áreas revisadas pelo National Reading Panel (NRP), trabalho solicitado pelo governo dos Estados Unidos com o objetivo de avaliar as pesquisas e evidências existentes e encontrar as melhores maneiras de ensinar as crianças a ler. A fluência foi definida pelo relatório como a "... habilidade de ler um texto rapidamente, precisamente e com expressão adequada” (2000, pp. 3-5). Atualmente, mesmo com o crescimento das pesquisas, a fluência segue sendo um tema controverso. Por um lado, parece haver um consenso crescente de que precisão, automaticidade e prosódia contribuem para o construto fluência (Hudson et al., 2005; Navas et al., 2009; Kuhn et al., 2010; Basso et al., 2018). Por outro, as definições enfatizam de modo variável tais componentes e ainda não deixam claro se a fluência contribui para a compreensão, ou se a compreensão promove fluência, ou, ainda, se a relação é recíproca. Cabe, desse modo, examinar como as diferentes definições de fluência de leitura abordam a relação entre fluência e compreensão.

Este artigo objetiva (1) realizar uma revisão integrativa do construto de fluência de leitura para (2) responder à questão: como as diferentes definições de fluência abordam a relação entre fluência e compreensão? Inicialmente serão abordados os componentes de precisão, automaticidade e prosódia. Em seguida, serão descritas algumas das definições de leitura fluente disponíveis na literatura, verificando-se o papel que destinam à fluência na leitura compreensiva. Também serão apresentadas as formas de avaliação da habilidade, assim como estudos de intervenção em fluência. Tais aspectos lançam luz sobre a questão da relação entre fluência e compreensão de leitura. Finalmente, serão discutidas implicações educacionais das diferentes considerações sobre a relação entre fluência e compreensão leitora.

\section{Componentes da fluência de leitura}

A falta de fluência é caracterizada por uma leitura que se encontra nos níveis iniciais de aquisição, sendo a decodificação lenta e ainda não automática. O leitor disfluente ignora a pontuação e exibe uma leitura sem expressão, monótona (Navas et al., 2009). As autoras apontam que as crianças em fase de alfabetização tendem a ler de forma mais lenta, uma vez que o processamento ocorre pela rota fonológica de conversão grafema-fonema. À medida que elas realizam a decodificação de forma fluente, lendo com velocidade progressivamente maior, passam a ler mais e se familiarizam com a forma visual das palavras encontradas frequentemente. Isso constrói um léxico mental com a representação ortográfica das palavras mais familiares, o que permite ao leitor fazer o reconhecimento visual direto das palavras, sem necessidade de mediação fonológica (Navas et al., 2009). A criança, desse modo, 
passa a realizar a leitura preferencialmente pela rota lexical (Coltheart, 2013), o que caracteriza a leitura fluente. A fluência, portanto, é demonstrada durante a leitura através da facilidade de reconhecimento de palavras, ritmo, fraseado e entonação do discurso, envolvendo precisão, automaticidade e prosódia (Kuhn et al., 2010), componentes descritos a seguir.

\section{Precisão}

A precisão na leitura refere-se à habilidade de reconhecer as palavras de forma correta, isto é, de realizar adequadamente a decodificação grafema-fonema (Basso et al., 2018). Alta compreensão do princípio alfabético, capacidade de combinar sons e o conhecimento de um banco de palavras de alta frequência na língua são algumas habilidades necessárias para a precisão no reconhecimento de palavras. Durante esse processo, os leitores precisam ser hábeis para 1) identificar os sons representados pelas letras ou combinações de letras, 2) combinar fonemas, 3) ler fonogramas (padrões comuns em palavras) e 4) usar letra-som e a sugestão de significado para determinar exatamente a pronúncia e o significado da palavra que está no texto (Hudson et al., 2005). A baixa precisão no reconhecimento de palavras tem uma influência negativa na compreensão da leitura. Um leitor sem precisão, que lê as palavras de forma incorreta, não terá acesso ao significado do texto expresso pelo autor, o que o conduzirá a interpretações equivocadas (Hudson et al., 2005).

\section{Automaticidade}

A automaticidade refere-se à habilidade de executar rapidamente uma atividade complexa utilizando poucos recursos de atenção, sendo resultado de prática prolongada (Basso et al., 2018). De acordo com Kuhn et al. (2010), o reconhecimento automático é central para o desenvolvimento da leitura fluente. Para as autoras, os processos são considerados automáticos quando possuem quatro propriedades: velocidade, ausência de esforço, autonomia e ausência de atenção consciente.

A velocidade é um dos aspectos principais que caracterizam a automaticidade da leitura, sendo que sua melhora indica o desenvolvimento da fluência (Basso et al., 2018). Ela surge simultaneamente com a precisão conforme o leitor envolve-se na prática da leitura. À medida que a automaticidade se desenvolve, o desempenho do leitor torna-se preciso e também mais rápido. Como citado anteriormente, as crianças em processo de alfabetização leem de forma lenta e, com o avanço do processo de decodificação, familiarizam-se com a forma visual das palavras, tornando-se mais precisas e passando a ler com mais velocidade (Navas et al., 2009). No entanto, esse aumento de velocidade não é ilimitado, existindo uma curva de aprendizado, conhecida como lei de potência, que indica quando o limite é alcançado. Desse modo, a velocidade aumenta ao longo da prática de leitura, mas os ganhos são maiores no início e se estabilizam com a prática de leitura adicional (Puliezi \& Maluf, 2014; O’Connor, 2018).

A ausência de esforço refere-se à facilidade com que uma tarefa é executada e à capacidade de realizar uma segunda tarefa enquanto a primeira é executada de forma automática. Ela é caracterizada pela decodificação sem esforço, permitindo focalizar a atenção no processo de compreensão (Basso et al., 2018). Quando o reconhecimento de palavras é ineficiente, são consumidos recursos cognitivos importantes para a compreensão, sendo ela prejudicada. No entanto, com a automatização de processos de nível inferior, como o reconhecimento de palavras, o leitor pode dedicar sua atenção à leitura com compreensão - habilidade de nível superior. Por outro lado, os leitores disfluentes não conseguem integrar as habilidades de nível inferior com as de nível superior, em virtude do esforço dedicado ao reconhecimento de palavras (Kuhn et al., 2010).

A automaticidade também envolve a autonomia. Ou seja, os processos automáticos também são autônomos, ocorrendo sem intenção, iniciando-se e finalizando-se independentemente da intenção do indivíduo. No caso da leitura, os leitores fluentes leem sem que tenham decidido realizar o ato. Isso ocorre, por exemplo, quando o leitor involuntariamente lê o texto que aparece na parte inferior de um 
programa de notícias, embora possa usar seus recursos cognitivos para inibi-lo, o que não ocorre com leitores iniciantes (Kuhn et al., 2010; Basso et al., 2018).

A ausência de atenção consciente refere-se à falta de consciência na decodificação. À medida que a habilidade de reconhecimento de palavras torna-se automática, a consciência das sub-habilidades que as compõe desaparece. Conforme Kuhn et al. (2010), essa falta de percepção consciente no reconhecimento de palavras diferencia os leitores fluentes dos disfluentes. Estes tendem a estar profundamente cientes das etapas que devem executar para reconhecer as palavras de um texto, o que torna o processo lento. No entanto, para os leitores fluentes, a decodificação é automática, havendo o reconhecimento das palavras sem esforço consciente, o que facilita a compreensão.

\section{Prosódia}

Embora a automaticidade seja considerada central para o desenvolvimento da fluência, ela não explica todos os aspectos do construto. Outro componente crítico da leitura fluente é a capacidade de ler com prosódia (Kuhn et al., 2010). A prosódia na leitura refere-se a expressão, ritmo e entonação do discurso, sendo considerada a musicalidade da linguagem oral (Basso et al., 2018). Refere-se à capacidade de ler um texto respeitando a pontuação, com expressão e entonação adequadas, o que permite a manutenção do significado (Kuhn et al., 2010). Entre as características importantes da prosódia na leitura estão: entonação, acento e intensidade, duração e pausas. Tais elementos sinalizam dúvida, surpresa, certeza, entre outras modalidades, além da semântica (Basso et al., 2018).

A entonação refere-se à frequência da fala, o que corresponde às mudanças perceptíveis na altura melódica (Puliezi \& Maluf, 2014). Na fala, as sentenças são geralmente marcadas por uma elevação inicial e, em seguida, uma declinação da entonação. Quando as sentenças são mais longas, há um enfraquecimento geral da entonação. As crianças, quando leem sentenças longas ou complexas, tendem a apresentar um declínio da entonação no final das frases, por exemplo. Uma frase com uma entonação crescente sugere ao ouvinte que essa frase ou expressão terá continuidade, e uma entonação decrescente é indicativa de uma pausa ou do fim de um enunciado (Kuhn et al., 2010).

O acento e a intensidade são igualmente componentes da prosódia (Basso et al., 2018). A acentuação tônica é importante na pronúncia porque alguns idiomas são caracterizados pela tonicidade predominante das palavras. Em português, a maioria das palavras é paroxítona, e muitas das palavras que não o são são sinalizadas graficamente. A tonicidade pode ser usada para distinguir formas gramaticais, como, por exemplo, "sede" (vontade de beber) e "sede" (residência) (Puliezi \& Maluf, 2014). No entanto, de acordo com as autoras, cada idioma segue seu próprio padrão tônico; portanto, ao avaliar a prosódia na leitura, é preciso considerar os padrões familiares de acentuação associados ao idioma falado (Kuhn et al., 2010).

Outra característica da prosódia é a duração da articulação de um som, sílaba ou enunciado (Puliezi \& Maluf, 2014), devendo-se considerar a taxa geral de fala do orador, pois ela varia conforme a velocidade de elocução. Desse modo, as durações de segmento de leitores mais velozes serão mais curtas do que as de leitores mais lentos (Puliezi \& Maluf, 2014). A duração da sílaba, por exemplo, será mais curta conforme os leitores prossigam em frases longas. Isso significa que uma criança instruída a ler rapidamente mostrará menos evidências de marcação de acentuação e alongamento final da frase (Kuhn et al., 2010).

A última característica da prosódia são as pausas, sendo elas consideradas as unidades de tempo nas quais não há fonação (Puliezi \& Maluf, 2014). Conforme as autoras, são dois os fatores que dão origem às pausas. Um deles é fisiológico, determinado pela capacidade limitada dos pulmões, sendo a pausa necessária para um novo armazenamento de ar. O segundo, e mais importante para a prosódia, se refere ao sentido. Ao compreender que toda oração é uma unidade de sentido, supõe-se que ela é formada por unidades significativas menores, como as palavras que estão conectadas pela semântica 
e pela sintaxe ao redor de um núcleo, de maneira que, durante a leitura, são delimitadas por pausa. Quando a frase lida não tem pausas, ou quando elas ocorrem em locais inapropriados do texto, a leitura torna-se irregular (Kuhn et al., 2010; Basso et al., 2018).

\section{Definições de fluência de leitura}

Tendo apresentado os componentes precisão, automaticidade e prosódia, atualmente apontados na literatura como importantes para a fluência de leitura (Hudson et al., 2005; Navas et al., 2009; Kuhn et al., 2010; Basso et al., 2018), serão descritas a seguir as diferentes maneiras pelas quais a fluência é definida e como elas abordam a relação com a compreensão. Tal discussão é importante, pois em muitas pesquisas seus componentes ainda parecem ser enfatizados de forma distinta, o que traz implicações ao ensino e à avaliação da habilidade. Enquanto muitas definições de fluência destacam a importância da precisão, da automaticidade e da prosódia em relação à compreensão do texto, os elementos enfatizados e o papel atribuído a esses componentes no desenvolvimento da leitura proficiente variam amplamente entre as pesquisas (Kuhn et al., 2010).

\section{Fluência como precisão e automaticidade}

A definição enfatiza o reconhecimento preciso e automático de palavras e componentes específicos, como a consciência fonêmica e a correspondência letra-som, isto é, habilidades que permitem a identificação correta e rápida das palavras (Fletcher et al., 2009). Kuhn et al. (2010) apontam que o reconhecimento preciso e automático de palavras é um componente crítico da leitura fluente, sendo que a consciência fonêmica, a nomeação de letras, entre outros componentes, contribuem para o desenvolvimento e a consolidação do reconhecimento de palavras pelos alunos. De acordo com as autoras, a precisão e a automaticidade desempenham um papel central na leitura fluente. No entanto, argumentam que a ênfase dada a esses componentes costuma ocorrer porque eles são elementos mais quantificáveis da fluência e que expressão, ritmo e entonação, isto é, prosódia, tende a ser desconsiderada.

Estudos empíricos que avaliam a fluência por meio de medidas de precisão e automaticidade apontam correlações significativas com a compreensão leitora. Kang e Shin (2019) recentemente avaliaram 329 alunos estadunidenses (idade média de 9,8 anos) do $4^{\circ}$ ano do ensino fundamental com dificuldade em leitura. No estudo, todas as correlações entre as medidas de compreensão e fluência foram estatisticamente significativas. Entre as três medidas de compreensão, o teste WJ3-PC (Woodcock et al., 2001), que envolve o preenchimento de lacunas do texto com palavras que fazem sentido, mostrou as mais fortes correlações com a fluência $(.53 \mathrm{p}<.001)$.

Embora em muitas pesquisas os elementos precisão e automaticidade sejam considerados centrais para a fluência da leitura, eles não são os únicos elementos críticos apontados por pesquisadores (Hudson et al., 2005; Basso et al., 2019). Como foi possível verificar, a prosódia garante expressão, ritmo e entonação do discurso, estando relacionada à compreensão (Arcand et al., 2014).

\section{Fluência como prosódia}

A National Assessment of Educational Progress (Naep) ${ }^{1}$ considera o desempenho em leitura oral como um indicador importante da leitura proficiente. No entanto, embora inclua medidas de precisão e velocidade como parte de sua avaliação, separa a fluência como um componente distinto, definindo-a como “. . . fraseado, adesão à sintaxe e expressividade do autor” (Daane et al., 2005, p. 5), equiparando a fluência às definições de prosódia. Kuhn et al. (2010) explicam que essa distinção pode ser encontrada no contexto histórico da avaliação, sendo a Naep uma das primeiras avaliações em larga 
escala do desempenho da leitura oral realizada quando a fluência ainda era um componente negligenciado. Nas poucas pesquisas em que o construto foi considerado, eram enfatizadas velocidade e precisão, sendo medidas pelo número de palavras lidas corretamente por minuto (taxa da leitura). Desse modo, um dos objetivos originais da Naep era descrever os aspectos da leitura oral que iam além da precisão e velocidade. Ao projetar a Escala de Fluência de Leitura Oral, os autores da Naep esperavam contrabalançar parte da ênfase em velocidade e precisão, além de integrar elementos da linguagem oral nas discussões que envolviam o desempenho em leitura. Desse modo, ao longo das edições da avaliação, é possível verificar a ênfase dada aos elementos prosódicos na maioria das definições de fluência. É importante, no entanto, manter uma definição integrada de fluência que inclua precisão, automaticidade e prosódia. Uma definição que separa velocidade e precisão pode reforçar a posição de que a taxa da leitura pode ser tratada como uma medida isolada do desempenho na leitura oral (Kuhn et al., 2010).

Estudos empíricos que se dedicam à avaliação da prosódia evidenciam que o construto está significativamente correlacionado à compreensão leitora. Klauda e Guthrie (2008) avaliaram 278 crianças estadunidenses de $5^{\circ}$ ano do ensino fundamental. Os autores verificaram que as mudanças na prosódia estavam reciprocamente relacionadas às mudanças na compreensão leitora ao longo do ano. Em outra direção, Arcand et al. (2014) avaliaram 261 alunos canadenses de $2^{\circ}$ ano do ensino fundamental. Os autores verificaram se a leitura prosódica facilitaria a compreensão leitora em um modelo em que vocabulário, automaticidade e precisão na leitura foram controlados. No estudo, as duas medidas de prosódia foram preditoras da compreensão leitora.

\section{Fluência como leitura proficiente}

Outra definição de fluência tende a equipará-la à leitura proficiente, em que a característica mais importante do leitor fluente é a habilidade de decodificar e compreender o texto simultaneamente. Precisão no reconhecimento de palavras, automaticidade e capacidade de ler oralmente com expressão seriam apenas indicadores de que a leitura proficiente foi alcançada (Samuels, 2006). Conforme Kuhn et al. (2010), ao incluir a compreensão na definição de leitura fluente, seria possível diferenciar dois grupos de leitores, os wordcallers, aqueles que simplesmente leem as palavras sem atentar ao significado, e os leitores fluentes, que constroem o significado com base no texto enquanto leem. De acordo com as autoras, embora os leitores wordcallers não sejam a maioria, seu número aumenta no ensino fundamental. Desse modo, o ensino que se dedica à velocidade e à precisão do reconhecimento de palavras com pouca ou nenhuma consideração à compreensão servirá para aumentar a quantidade de alunos que leem sem compreender (Kuhn et al., 2010).

A leitura proficiente é complexa e requer a coordenação de diferentes informações, incluindo conhecimento sintático, ortográfico, de vocabulário, fatores afetivos, entre outros que permitem ao leitor construir significado com base no texto (Kuhn et al., 2010). Para as autoras, assim como a fluência dos leitores pode variar conforme o texto, ou seja, os leitores podem ser capazes de ler alguns textos com boa fluência, mas ser disfluentes ao ler textos difíceis em termos de vocabulário ou conteúdo, também é possível que a compreensão de textos difíceis varie, apesar da leitura do texto com fluência adequada.

\section{Fluência relacionada reciprocamente com a compreensão}

Essa definição considera uma relação recíproca entre fluência e compreensão leitora (Chard et al., 2006). Desse modo, o construto contribuiria e possivelmente resultaria do entendimento do texto pelos leitores. Os componentes da fluência como automaticidade e prosódia facilitariam e se beneficiariam da compreensão. Kuhn et al. (2010) apontam que tal definição afasta-se de uma conceitualização superficial da fluência, que compreende o construto como um fenômeno principalmente da leitura oral e, como resultado, tende a enfatizar os seus elementos mais concretos por meio do ensino e avaliação. Isso é importante pois a maioria das leituras é realizada de forma silenciosa e não oral (Kuhn et al., 2010). 


\section{Fluência como precisão, automaticidade e prosódia facilitando a compreensão}

Ainda é possível encontrar na literatura outra definição de leitura fluente. Nessa definição, a fluência combina precisão, automaticidade e prosódia de leitura oral. Tais componentes facilitariam a construção de significados pelo leitor, ou seja, a compreensão (Kuhn et al., 2010). Para as autoras, a fluência seria demonstrada durante a leitura oral por meio da facilidade no reconhecimento de palavras, no ritmo, fraseado e entonação do discurso. A fluência também seria um fator tanto da leitura oral quanto da leitura silenciosa que pode limitar ou apoiar a compreensão.

Conforme Kuhn et al. (2010), mesmo que essa definição seja influenciada por outras (Harris \& Hodges, 1995; Chard et al., 2006), ela objetiva incluir vários pontos críticos da fluência. Destaca, em primeiro lugar, a relação entre fluência e compreensão. Segundo, descreve a prosódia juntamente com o reconhecimento preciso e automático de palavras, sem privilegiar nenhum dos componentes. Em terceiro lugar, aponta que a fluência desempenha um papel tanto na leitura silenciosa quanto na leitura oral.

\section{Avaliação da fluência de leitura}

Além das diferentes definições de fluência, há na literatura distintas formas de avaliar o construto. Enquanto alguns estudos empíricos medem precisão e automaticidade, outros incluem a prosódia em suas avaliações. As diferentes formas de avaliar a fluência, além de evidenciar o entendimento em relação ao construto, também influenciam o modo como se entende a relação com a compreensão de leitura.

A avaliação da fluência leitora pode ser realizada nos níveis da palavra, sentença ou texto. De acordo com Basso et al. (2018), a investigação do construto por meio da leitura de palavras isoladas está relacionada à velocidade de processamento dos sistemas cerebrais ativados durante a leitura. $\mathrm{Na}$ avaliação da fluência de leitura de sentenças e textos são contempladas as dimensões de precisão (capacidade de reconhecimento de palavras), automaticidade (velocidade de processamento) e prosódia (intensidade, duração, ritmo, expressão e entonação), ou seja, as três dimensões da fluência e ainda a compreensão. A inclusão da compreensão em medidas de fluência ainda é controversa, entretanto pesquisadores apontam que ela é uma medida importante na avaliação em virtude de sua relação com a fluência (Daane et al., 2005; Navas et al., 2009; Basso et al., 2018). Nesse tipo de avaliação, são medidas a porcentagem de palavras lidas corretamente, a taxa de leitura oral, a adequação de pausas, ritmo e entonação e a compreensão com base em questionário sobre o texto lido (Basso et al., 2018). A investigação da fluência por meio da leitura de sentenças ou textos é considerada uma medida mais completa, pois apenas por meio dela é possível medir aspectos prosódicos como entonação, acento e intensidade, duração e pausas. De acordo com o National Reading Panel (2000), é indispensável uma avaliação detalhada da fluência para descartar possíveis falhas no funcionamento de uma de suas dimensões, assim como para estruturar programas de intervenção.

Basso et al. (2018) apontam que, na avaliação da fluência, cada tipo de tarefa tem a sua especificidade, pois a fluência de leitura de palavras e a de tex to medem construtos diferentes. Enquanto a avaliação da fluência por meio da leitura de lista de palavras está mais relacionada à proficiência no reconhecimento de palavras, a fluência de leitura textual relaciona-se ao processamento de informações no nível da palavra e além dela. Na leitura de textos, as palavras fazem parte de um contexto e, desse modo, podem ser lidas mais rapidamente do que as palavras em lista, que não estão relacionadas entre si. A avaliação da fluência através da leitura de textos evidencia o entendimento de que fluência e compreensão estão relacionadas. Estudos também apontam que a avaliação da fluência de leitura textual está mais fortemente correlacionada à compreensão leitora do que a avaliação pela leitura de lista de palavras isoladas (Fuchs et al., 2001).

Por ser uma habilidade ainda pouco investigada no Brasil, há escassez de instrumentos normatizados que avaliam a fluência leitora no país, sendo ainda mais escassos os instrumentos que avaliam a fluência de leitura textual (Basso et al., 2018). Entre os estudos que investigaram o construto, é possível encontrar, sobretudo, pesquisas que se dedicaram à fluência de listas de palavras isoladas. 
No entanto, recentemente foi incluído na coleção Anele - Avaliação Neuropsicológica da Leitura e da Escrita, a Avaliação da Fluência de Leitura Textual (AFLeT) (Basso et al., 2018), um instrumento breve, padronizado e normatizado que avalia todos os componentes envolvidos na fluência (precisão, automaticidade e prosódia) e ainda a compreensão, caracterizando-se como um dos únicos instrumentos brasileiros que avaliam o construto de forma ampla. O instrumento é destinado a crianças de 7 a 10 anos, alunos de $2^{\circ}$ a $4^{\circ}$ ano escolar do ensino fundamental de escolas públicas e privadas. Tem como objetivo avaliar as habilidades de fluência textual de um texto narrativo e também identificar possíveis dificuldades em fluência de leitura oral. Pode ser utilizado por profissionais da saúde e educação, incluindo médicos, psicólogos, fonoaudiólogos, terapeutas ocupacionais, psicopedagogos e professores.

A aplicação do instrumento consiste na leitura em voz alta de um texto narrativo e, em seguida, a resposta a um questionário de múltipla escolha. $\mathrm{Na}$ avaliação são computados o número de palavras lidas por minuto, os tipos de erro de precisão, o número de palavras lidas corretamente por minuto, erros de pausa, entonação e fluidez, entre outras variáveis. Os resultados dos estudos psicométricos mostram que o AFLeT é uma importante medida de avaliação da fluência, pois permite identificar diferenças de desempenho conforme critérios de idade, escolaridade, tipo de escola, nível socioeconômico e dificuldades de leitura, sugerindo evidências de validade de critério (Piccolo et al., 2018). Os escores da amostra normativa também se correlacionaram significativamente com a leitura de palavras e pseudopalavras isoladas, fluência de leitura de palavras isoladas e nomeação seriada rápida de letras, figuras e números. Os estudos de consistência interna e de concordância entre avaliadores também apontam evidências de fidedignidade para o instrumento (Sbicigo et al., 2018).

\section{Estudos de intervenção em fluência de leitura}

Assim como os instrumentos de avaliação da habilidade, estudos de intervenção em fluência de leitura ainda são escassos na literatura. Em muitas pesquisas as técnicas de instrução também não enfocam todos os componentes do construto (precisão, automaticidade e prosódia), sendo a prosódia o componente que menos tende a ser alvo de intervenção. Mesmo assim, os estudos evidenciam importantes correlações com a habilidade de compreender, o que é importante no entendimento da direção da relação entre fluência e compreensão de leitura.

No estudo de Amendum et al. (2015), 636 crianças estadunidenses (idade média de 6,5 anos) de $1^{\circ}, 2^{\circ}$ e $3^{\circ}$ ano do ensino fundamental receberam instruções baseadas em programas de leitura como, por exemplo, o Scott Foresman Reading (Afflerbach et al., 2002). As instruções, ministradas pelos professores das turmas, envolveram consciência fonêmica, conhecimento fonético, fluência, vocabulário e compreensão de leitura. Foram utilizados materiais de revisão, textos de alunos e livros diversos. Os alunos também participaram diariamente de aulas de leitura em pequenos grupos. Ao final do ano letivo, aproximadamente $25 \%$ das crianças de cada uma das 147 salas de aula foram avaliadas. A avaliação constituiu-se de leitura em voz alta de sentenças progressivamente difíceis seguidas de questões de compreensão. Para avaliar a fluência, foi medida a porcentagem de palavras lidas corretamente (precisão) e a taxa de leitura (velocidade). Com base na avaliação, os alunos foram divididos em dois grupos: alunos com leitura no nível da série e alunos com leitura acima do nível (Amendum et al., 2015).

Os resultados das análises evidenciaram que houve relação significativa entre a taxa de leitura e a compreensão, mas a relação variou pelo nível de texto. Houve também uma relação significativa fraca entre precisão e compreensão, mas a relação também variou de acordo com o nível de texto. As análises de covariância (Ancova), com a compreensão como variável dependente, também evidenciaram que, conforme a taxa de leitura dos alunos com leitura no nível da série aumentou, as pontuações em compreensão aumentaram (de 70,77\% para $81,01 \%$ ). Os resultados também mostraram que, em ambos os grupos de alunos, à medida que a precisão na leitura aumentou, a compreensão textual também aumentou. Para aqueles com leitura acima do nível, à medida que a precisão aumentou, a compreensão aumentou significativamente (25,71\%) (Amendum et al., 2015). 
Em um estudo brasileiro mais recente (Martins, 2018), 30 alunos (entre 8 e 11 anos) com dificuldade de leitura, de $3^{\circ}, 4^{\circ}$ e $5^{\circ}$ ano do ensino fundamental de uma escola pública do município de São Paulo foram submetidos à avaliação de fluência e compreensão leitora. Após o pré-teste, os alunos receberam instrução em fluência, que consistiu na aplicação da versão traduzida do programa Helping Early Literacy with Practice Strategies (Helps) (Begeny, 2009). Foram 30 sessões de 10 minutos três vezes por semana. As estratégias incluíram leituras cronometradas repetidas, modelagem, correção de erros na frase, estímulos verbais, definição de metas, feedback e sistema motivacional por recompensa (Martins, 2018). Ao final da intervenção, fluência e compreensão foram novamente avaliadas. Foram medidas precisão e taxa de leitura (automaticidade) com base em um minuto de leitura de um texto narrativo. Para avaliação da fluência, também foi utilizado o subteste de leitura de palavras do Protocolo de Avaliação de Habilidades Cognitivo-linguísticas (Capellini et al., 2012), que consiste na leitura de 40 palavras reais. Para avaliar a compreensão, foi utilizado o Protocolo de Avaliação da Compreensão da Leitura (Cunha \& Capellini, 2014), em que os alunos realizaram a leitura de um texto seguido de questões literais e inferenciais (Martins, 2018).

O pós-teste evidenciou que, em relação à compreensão leitora, somente os alunos do $3^{\circ}$ ano do grupo experimental apresentaram diferença estatisticamente significativa entre o pré e o pós-teste, enquanto para os alunos de $4^{\circ}$ e $5^{\circ}$ ano observou-se discreta diminuição nos erros de respostas nas questões de compreensão. Martins (2018) sugere que os alunos com dificuldades em fluência melhoraram seu desempenho em leitura e, consequentemente, o desempenho em compreensão.

Em síntese, os estudos apresentados não evidenciam correlações significativas fortes e claras com a compreensão leitora. As variações nas medidas utilizadas também fazem com que muitos estudos apresentem resultados divergentes. Como foi possível verificar, não foram incluídas medidas de avaliação da prosódia nos estudos de intervenção citados. No entanto, além de serem habilidades correlacionadas, autores apontam que a prosódia é a dimensão da fluência que mais evidencia se o leitor compreendeu um texto, uma vez que o uso apropriado dos elementos prosódicos fornece evidências de que o leitor compreende o que está sendo lido (Kuhn et al., 2010). Ou seja, incluir medidas de instrução e avaliação da prosódia nesses estudos poderia evidenciar relações mais claras e consistentes com a compreensão leitora.

\section{Discussão dos achados e implicações educacionais}

Ao tentar responder à questão que originou este artigo - "Como as diferentes definições de fluência abordam a relação entre fluência e compreensão?” -, percebe-se que a falta de consenso nas definições de fluência se dá pela diferenciação de destaque às variáveis subjacentes a esse construto, ou melhor, ainda não há uniformidade sobre quais variáveis compõem a fluência. Em alguns estudos, ela é definida como automaticidade e precisão, e, em outros, como prosódia. Provavelmente, em função disso, a direção da relação entre fluência e compreensão não esteja claramente estabelecida. Diferentes pesquisas não deixam claro se a fluência é causa, consequência ou se têm uma relação recíproca com a compreensão (Kuhn \& Stahl, 2003). Há na literatura evidências que apoiam as distintas posições (Schwanenflugel et al., 2004; Klauda \& Guthrie, 2008; Arcand et al., 2014).

Acredita-se que a superação de tais pontos controversos é fundamental para a expansão desse tema de pesquisa, sobretudo pelas implicações educacionais inerentes a ele. $\mathrm{O}$ ensino em sala de aula se desenvolve em torno do entendimento que os professores têm sobre o construto, ou seja, o modo como eles veem aspectos do processo de leitura tem um papel decisivo no ensino e também na avaliação. Além disso, as diferentes formas como o professor desenvolve o ensino e a avaliação em sala de aula afetam fortemente a compreensão dos alunos sobre o que é ler e o que significa ser um leitor (Kuhn et al., 2010).

Ao enfatizar, por exemplo, os elementos mais quantificáveis da fluência, como precisão e automaticidade, corre-se o risco de direcionar os esforços educacionais ao desenvolvimento do 
reconhecimento de palavras apenas. Ao focar velocidade de decodificação em detrimento da prosódia, os alunos podem ser incentivados a ler o mais rápido possível, sem expressão, ritmo e entonação. Destaca-se, assim, a importância de se considerar uma visão ampla de fluência de leitura, englobando também os seus elementos menos quantificáveis. A fluência, desse modo, envolve precisão, automaticidade e prosódia, componentes que, juntos, podem atuar no sentido de facilitar ou limitar a compreensão leitora.

Nesse ponto, levantam-se as questões: Qual seria a consequência para o ensino de pensar essa habilidade como causa da compreensão? Ou se a fluência é vista como consequência? Ou se se entende uma relação recíproca? Acredita-se que, ao entender a fluência como causa da compreensão leitora, corre-se o risco de direcionar o ensino apenas para o desenvolvimento da decodificação, pois os alunos precisariam, em primeiro lugar, ler as palavras com precisão e velocidade adequadas para, então, ler e compreender textos. Nas escolas, muitos professores acreditam que não podem disponibilizar textos para alunos em fase de alfabetização, pois estes ainda não leem com fluência. Nessa direção, é indispensável incluir a prosódia, pois, como foi possível verificar, a leitura com ritmo, expressão e entonação desenvolve-se por meio da leitura de sentenças e textos, estando associada à compreensão (Kuhn et al., 2010).

Ao contrário, se se entende a fluência como resultante da compreensão, pode-se tirar o foco da decodificação e privilegiar a compreensão a partir da leitura de textos. No entanto, os alunos ainda imprecisos e não automáticos no reconhecimento de palavras não conseguiriam acessar os significados destas e, consequentemente, a compreensão global do texto. Sabe-se, entretanto, que só é possível extrair sentido de um texto se antes se pode ler as palavras de forma correta e com automaticidade suficiente para não sobrecarregar os recursos cognitivos necessários à compreensão (Kuhn et al., 2010).

Se há o entendimento de uma relação recíproca entre fluência e compreensão, em que a fluência contribuiria e possivelmente resultaria do entendimento do texto pelos leitores, é possível concluir que todos os domínios da leitura devem ser abordados ao mesmo tempo, desde o início da alfabetização. O que é importante, pois as crianças não devem ser ensinadas apenas a decodificar de forma precisa e automática, mas também a compreender o que leem. Acredita-se que a presença do subcomponente prosódia na definição de fluência interfere de forma decisiva na consideração da relação entre fluência e compreensão leitora. Ao considerar a prosódia, fica claro que algum nível de compreensão é necessário para a leitura fluente. Como foi possível verificar, estudos empíricos mostram que a prosódia tem um papel fundamental na compreensão da leitura. Arcand et al. (2014), após controlar vocabulário, automaticidade e precisão, verificaram que as medidas de prosódia foram preditoras da compreensão leitora no $2^{\circ}$ ano do ensino fundamental. No estudo de Klauda e Guthrie (2008), as mudanças na prosódia estavam reciprocamente relacionadas às mudanças na compreensão leitora ao longo do $5^{\circ}$ ano.

Tais estudos mostram que provavelmente a relação entre fluência e compreensão se modifique ao longo do desenvolvimento da leitura, de modo que, nos primeiros anos de escolarização, a leitura com fluência seria ponte para compreensão, isto é, contribuiria para o entendimento do texto; pois, enquanto a criança utiliza todos os seus recursos atencionais e de memória para a decodificação, ela fica impedida de realizar processos de alto nível envolvidos na compreensão, como, por exemplo, as inferências. À medida que a habilidade de ler se desenvolve, com ganho de automaticidade, provavelmente a relação entre fluência e compreensão se torne recíproca, ou seja, quanto mais fluente o leitor se torna, melhor a sua compreensão, do mesmo modo que quanto mais compreende, melhor a sua fluência. Sendo assim, o ensino da leitura precisa ir se modificando à medida que a habilidade de ler se desenvolve, ou seja, as ênfases podem mudar conforme os alunos aprimoram a sua competência leitora (Snow \& Juel, 2013), pois os processos cognitivos que explicam a proficiência na leitura se diferenciam à medida que a habilidade se desenvolve (Corso et al., 2013). No entanto, a compreensão precisa ser entendida como o objetivo da leitura, de modo que essa ideia deve permear mesmo as etapas iniciais de ensino, ainda que, inicialmente, o foco seja o reconhecimento de palavras. Desse modo, acredita-se que a fluência de leitura envolve precisão, automaticidade e prosódia, componentes que, juntos, estão reciprocamente relacionados à compreensão leitora. 
Infere-se, desse modo, que a prosódia nem sempre ganha destaque nas definições de fluência porque a produção de conhecimento em leitura ainda se dá, de forma intensa, nos anos iniciais do ensino fundamental, cujo foco é o processo de alfabetização e decodificação. Acredita-se que, se as pesquisas futuras englobarem leitores já mais hábeis, alunos dos anos finais do ensino fundamental e do ensino médio poderão colaborar para a busca de refinamento da definição de fluência, verificando, nesses níveis, como se dá o equilíbrio entre os diferentes componentes do construto (precisão, automaticidade e prosódia), bem como as relações com a compreensão de leitura nas etapas mais avançadas de escolaridade.

\section{Considerações finais}

As diferentes posições em relação à fluência têm implicações importantes no ensino e na avaliação da habilidade, demandando cautela ao tentar definir o construto. Como as pesquisas em fluência são recentes, as controvérsias em torno dessa habilidade são esperadas e sinalizam a necessidade de continuação das investigações. No entanto, apesar das controvérsias em torno do tema, as diferentes definições de fluência revelam uma evolução do construto, na medida em que é relativamente recente a distinção dos subdomínios da leitura (reconhecimento de palavras, fluência e compreensão). Estudos mais recentes, como os já citados, também evidenciam alguns consensos, como: 1) a definição de fluência precisa incluir prosódia, e não se restringe à automaticidade e precisão; 2) fluência e compreensão se relacionam, embora não haja dados definitivos sobre a direção dessa relação; 3) a fluência não é importante apenas para a leitura oral, pois a leitura silenciosa não fluente também impactaria a compreensão; 4) a avaliação de leitura precisa incluir medidas de fluência, ou seja, medidas de avaliação da leitura oral; pois, se o aluno decodifica, não quer dizer que tenha fluência na leitura nem que compreenda o material lido; e 5) é importante trabalhar os três domínios da leitura, reconhecimento de palavras, fluência e compreensão.

Destaca-se, desse modo, a necessidade de direcionar as pesquisas em busca de melhor refinar e operacionalizar o conceito de fluência. Avançar nesse ponto pode representar um futuro promissor para a área de leitura, no que diz respeito ao ensino e à avaliação. $\mathrm{O}$ refinamento e a operacionalização da fluência permitirão o aprimoramento da natureza dos instrumentos que avaliam fluência e, consequentemente, a identificação inicial de possíveis dificuldades nessa habilidade. Assim, o delineamento de programas de intervenção efetivos, considerando as distintas variáveis subjacentes ao tema, pode ser elucidado. Vê-se, dessa maneira, que esse é um campo fértil de investigação tanto para a prevenção de dificuldades como para a intervenção em leitura.

\section{Referências}

Afflerbach, P., Scott Beers, J., Blachowicz, C. L. Z., Boyd, C. D., Cheyney, W., Diffilly, D., \& Wixon, K. (2002). Scott Foresman reading. Scott Foresman.

Amendum, S. J., Conradi, K., \& Liebfreund, M. D. (2015). The push for more challenging texts: An analysis of early readers' rate, accuracy, and comprehension. Reading Psychology, 37(4), 570-600. https://doi.org/ 10.1080/02702711.2015.1072609

Arcand, M.-S., Dion, E., Lemire-Théberge, L., Guay, M.-H., Barrette, A., Gagnon, V., Caron, P.-O., \& Fuchs, D. (2014). Segmenting texts into meaningful word groups: Beginning readers' prosody and comprehension. Scientific Studies of Reading, 18(3), 208-223. https://doi.org/10.1080/10888438.2013.864658

Basso, F. P., Alves, L. M., Miná, C. S., Piccolo, L. da R., \& Salles, J. F. de. (2018). Pressupostos teóricos que embasaram o desenvolvimento do instrumento Avaliação da Fluência de Leitura Textual (AFLeT). In F. P. Basso, C. S. Miná, L. da R. Piccolo \& J. F. Salles (Eds.), Avaliação da Fluência de Leitura Textual (AFLeT) (pp. 19-33). Vetor. 
Basso, F. P., Piccolo, L. da R., Miná, C. S., \& Salles, J. F. (2019). Instrumento de Avaliação da Fluência de Leitura Textual: Da decodificação à compreensão de leitura. Letras de Hoje, 54(2), 146-153. https:// doi.org/10.15448/1984-7726.2019.2.32519

Begeny, J. C. (2009). Helping Early Literacy with Practice Strategies (HELPS): A one-on-one program designed to improve students' reading fluency. The HELPS Education Fund.

Capellini, S. A., Smythe, I., \& Silva, C. da. (2012). Protocolo de avaliação de habilidades cognitivo-linguisticas. Book Toy.

Chard, D. J., Pikulski, J.J., \& Mcdonagh, S. H. (2006). Fluency: The link between decoding and comprehension for struggling readers. In T. Rasinski, C. Blachowicz, \& K. Lems (Eds.), Fluency instruction: Researchbased best practices (pp. 39-61). Guilford.

Coltheart, M. (2013). Modelando a leitura: A abordagem da dupla rota. In M. Snowling, \& C. Hulme (Eds.), A ciência da leitura (pp. 24-41). Penso.

Corso, H. V., Sperb, T. M., \& Salles, J. F. de. (2013). Leitura de palavras e de texto em crianças: Efeitos de série e tipo de escola, e dissociações de desempenhos. Letras de Hoje, 48(1), 81-90. https://revistaseletronicas. pucrs.br/ojs/index.php/fale/article/view/12033

Corso, H. V., Sperb, T. M., Piccolo, L. da R., Miná, C. S., \& Salles, J. F. de. (2017). Pressupostos teóricos que embasaram o desenvolvimento do instrumento de avaliação da compreensão de leitura textual para crianças (COMTEXT). In H. V. Corso, L. da R. Piccolo, C. S. Miná, \& J. F. de. Salles (Eds.). Avaliação da compreensão de leitura textual (COMTEXT) (pp. 17-29). Vetor.

Cunha, V. L. O., \& Capellini, S. A. (2014). PROCOMLE: Protocolo de Avaliação da Compreensão de Leitura. Book Toy.

Daane, M. C., Campbell, J. R., Grigg, W. S., Goodman, M. J., \& Oranje, A. (2005). Fourth-Grade Students Reading Aloud: NAEP 2002 special study of oral reading. U.S. Department of Education. Institute of Education Sciences, National Center for Education Statistics. Government Printing Office.

Fletcher, J. M., Lyons, R. G., Fuchs, L. S., \& Barnes, M. A. (2009). Transtornos de aprendizagem: Da identificação à intervenção. Artmed.

Fuchs, L. S., Fuchs, D., Hosp, M. K., \& Jenkins, J. R. (2001). Oral reading fluency as an indicator of reading competence: A theoretical, empirical, and historical analysis. Scientific Studies of Reading, 5(3), 239256. https://doi.org/10.1207/S1532799XSSR0503_3

Harris, T.L., \& Hodges, R.E. (1995). The literacy dictionary: The vocabulary of readingand writing. International Reading Association.

Hudson, R. F., Lane, H. B., \& Pullen, P. C. (2005). Reading fluency assessment and instruction: What, why, and how? The Reading Teacher, 58(8), 702-714. https://doi.org/10.1598/RT.58.8.1

Kang, E. Y., \& Shin, M. (2019). The contributions of reading fluency and decoding to reading comprehension for struggling readers in fourth grade. Reading \& Writing Quarterly, 35(3), 1-14. https://doi.org/10.1 $080 / 10573569.2018 .1521758$

Klauda, S. L., \& Guthrie, J. T. (2008). Relationships of three components of reading fluency to reading comprehension. Journal of Educational Psychology, 100(2), 310-321. https://doi.org/10.1037/00220663.100.2.310

Kuhn, M. R., \& Stahl, S. A. (2003). Fluency: A review of developmental and remedial practices. Journal of Educational Psychology, 95(1), 3-21. https://doi.org/10.1037/0022-0663.95.1.3

Kuhn, M. R., Schwanenflugel, P. J., \& Meisinger, E. B. (2010). Aligning theory and assessment of reading fluency: Automaticity, prosody, and definitions of fluency. Reading Research Quarterly, 45(2), 232-253. https://doi.org/10.1598/RRQ.45.2.4

Martins, M. A. (2018). Programa de fluência de leitura para escolares do $3^{\circ}$ ao $5^{\circ}$ ano: Tradução, adaptação e aplicação [Tese de Doutorado, Faculdade de Filosofia e Ciências, Universidade Estadual Paulista]. Repositório Institucional Unesp. https://repositorio.unesp.br/handle/11449/152976 
National Reading Panel. (2000). Teaching children to read: An evidence-based assessment of the scientific research literature on reading and its implications for reading instruction. National Institute of Child Health and Human Development.

Navas, A. L. G. P., Pinto, J. C. B. R., \& Dellisa, P. R. R. (2009). Avanços no conhecimento do processamento da fluência em leitura: Da palavra ao texto. Revista da Sociedade Brasileira de Fonoaudiologia, 14(4), 553-559. http://dx.doi.org/10.1590/S1516-80342009000400021

O'Connor, R. E. (2018). Reading fluency and students with reading disabilities: How fast is fast enough to promote reading comprehension? Journal of Learning Disabilities, 51(2), 124-136. https://doi. org/10.1177/0022219417691835

Piccolo, L. da R., Becker, N., Basso, F. P., Koltermann, G., Lima, M., Esteves, C., \& Salles, J. F. de. (2018). Evidências de validade baseadas na relação com outras variáveis e com construtos conceitualmente relacionados ao instrumento Avaliação da Fluência de Leitura Textual (AFLeT). In F. P. Basso, C. S. Miná, L. da R. Piccolo, \& J. F. de Salles (Eds.), AFLeT: Avaliação da Fluência de Leitura Textual. Avaliação neuropsicológica da leitura e escrita (pp. 51-67). Vetor.

Puliezi, S., \& Maluf, M. R. (2014). A fluência e sua importância para a compreensão da leitura. Psico-USF, 19(3), 467-475. https://doi.org/10.1590/1413-82712014019003009

Samuels, J. S. (2006). Reading fluency: Its past, present, and future. In T. Rasinski, C. Blachowicz, \& K. Lems (Eds.), Fluency instruction: Research-based best practices (pp. 3-16). Guilford.

Sbicigo, J. B., Piccolo, L. da R., Basso, F. P., Miná, C. S., Esteves, C., \& Salles, J. F. de. (2018). Evidências de fidedignidade do instrumento Avaliação da Fluência de Leitura Textual (AFLeT). In F. P. Basso, C. S. Miná, L. da R. Piccolo, \& J. F. de Salles (Eds.), AFLeT: Avaliação da Fluência de Leitura Textual (pp. 69-75). Vetor.

Schwanenflugel, P. J., Hamilton, A. M., Wisenbaker, J. M., Kuhn, M. R., \& Stahl, S. A. (2004). Becoming a fluent reader: Reading skill and prosodic features in the oral reading of young readers. Journal of Educational Psychology, 96(1), 119-129. https://doi.org/10.1037/0022-0663.96.1.119

Snow, C., \& Juel, C. (2013). O ensino de leitura para crianças: O que sabemos a respeito? In M. Snowling, \& C. Hulme (Eds.), A ciência da leitura (pp. 520-538). Penso.

Woodcock, R. W., Mcgrew, K. S., \& Mather, N. (2001). Woodcock-Johnson tests of achievement (3a ed.). Riverside.

\section{Nota sobre autoria}

Amanda Oliveira Meggiato realizou a revisão teórica e a redação do artigo sob orientação das autoras Helena Vellinho Corso e Luciana Vellinho Corso, que também contribuíram em sua estruturação e revisão, assim como na redação dos resultados e conclusões.

\section{Disponibilidade de dados}

Os dados subjacentes ao texto da pesquisa estão informados no artigo.

\section{Como citar este artigo}

Meggiato, A. O., Corso, H. V., \& Corso, L. V. (2021). Fluência de leitura: Evolução do construto e relações com a compreensão. Cadernos de Pesquisa, 51, Artigo e07797. https://doi. org/10.1590/198053147797 